\title{
THE BLOOD SUPPLY OF THE LUNG IN PULMONARY TUBERCULOSIS *
}

\author{
BY \\ LEON CUDKOWICZ† \\ From the Department of Medicine, Postgraduate Medical School, Hammersmith Hospital, London
}

(RECEIVED FOR PUBLICATION JANUARY 14, 1952)

Opinion appears to differ regarding the pathology of the vessels in lungs affected by miliary and chronic tuberculosis. Kaufmann (1929) emphasized obliterative changes in the pulmonary arteries. Boyd (1950) speaks of an endarteritis obliterans in vessels without specifying their origin. Calmette (1923) mentioned the formation of small pedunculated, pear-shaped " aneurysms of Rasmussen" in branches of the pulmonary artery which traverse the walls of tuberculous cavities. The same aneurysmal dilatations were also pointed out by Kaufmann. Pagel (Kayne, Pagel, and O'Shaughnessy, 1948), on the other hand, believes that younger tubercles, and even older foci, contain blood vessels. He contends that the cells participating in the formation of the tubercle are generally derived from elements of connective tissue "which have an inherent tendency to vessel formation." Thus young tuberculous tissue is rich in capillaries and older foci are vascularized at the periphery.

Coryllos (1933) speculated on the possible clinical significance of endarteritis in the pulmonary arteries, and thought that this was probably beneficial in controlling the activity of tubercle bacilli. $\mathrm{He}$ considered that collapse therapy accomplished the same purpose by reducing the pulmonary artery bed and resting the lung. The oxygen requirements of the tubercle bacillus would thus be interfered with and its activity curtailed. Cournand and Richards (1941) also attribute the benefits of collapse therapy to the reduction of oxygen and blood available to the tubercle bacilli in the affected lungs. Rich (1944) thinks it reasonable to presume that the exacting oxygen requirements of the tubercle bacillus play some part in limiting its multiplication in vivo, and particularly within tuberculous lesions. Although little is known of the rate at which oxygen diffuses into areas of

\footnotetext{
- Some of the material in this paper was included in a thesis accepted by the University of London for the degree of M.D. in December, 1950.

+ In receipt of a grant from the Medical Research Council.
}

caseous necrosis, it is not surprising that the baci周 do not proliferate in the centre of closed caseouts areas, whereas they often multiply at an enormouss rate as soon as abundant aeration is re-established, for example, when the lesion opens into a bronchits or blood vessel. Dubos (1950) states that the tubercle bacillus does not possess a glycolyt魚 mechanism and derives its energy wholely from aerobic processes.

Steinberg, McCoy, and Dotter (1950) carried out angiocardiography in therapeutically collapsed lung and noted delay in pulmonary blood flow wit crowding and displacement of the pulmonarō arteries.

It appears, therefore, that the changes in the vasculature of tuberculous lungs which have bee most frequently reported are lesions in the put monary arteries, and these appear to be an endap teritis or aneurysmal dilatation of the branches contact with cavity walls. Boyd implies' that the obliterative changes provide an important safe guard against the occurrence of haemorrhage.

As regards the bronchial arteries in pulmonat tuberculosis, Karsner and Ash (1912) and Ghoreye and Karsner (1913), during their investigations in the effects of experimental pulmonary embolizatio had shown that reduction in blood flow through the pulmonary artery and reduction in pulmonary artery pressure to zero led to compensatory dilatation the bronchial arterial bed with considerable augs mentation of blood flow through that systerf? Calmette (1923) considered the possib.lity that thes aneurysmal dilatations of the vessels in the walls of tuberculous cavities were in fact in bronchiat arterioles. Wood and Miller (1938), by taking radiographs of injected necropsy material, showe that dilated bronchial arteries were present in the walls of tuberculous cavities. They asserted that haemoptyses from such cavities consisted of oxygenated blood and were derived from the bronchial arteries. Wright (1938) postulated th $\overrightarrow{g t}$ proliferation of pulmonary connective tissue, hov 
ever caused, was accompanied by the development of new vessels derived from the bronchial arteries.

\section{MATERIA}

In the present study the vasculature of tuberculous lungs was examined after death in five cases.

The details of the cases are summarized in the following table.

TABLE

Detalls of Cases in Present Study

\begin{tabular}{c|c|c|c}
\hline $\begin{array}{c}\text { Case } \\
\text { No. }\end{array}$ & Sex & Age & Diagnosis at Necropsy \\
\hline 1 & M & 53 & $\begin{array}{c}\text { Left apical fibrocaseous tuberculous } \\
\text { cavitation and bilateral terminal } \\
\text { miliary dissemination }\end{array}$ \\
\hline 2 & F & 73 & $\begin{array}{c}\text { Bilateral senile fibrocaseous pulmonary } \\
\text { tuberculosis with acute renal involve- } \\
\text { ment }\end{array}$ \\
\hline 3 & M & 47 & $\begin{array}{c}\text { Right apical tuberculous cavitation and } \\
\text { non-tuberculous bronchopneumonia }\end{array}$ \\
\hline 5 & M & 45 & $\begin{array}{c}\text { Coronary thrombosis and left apical } \\
\text { fibrocaseous lesion }\end{array}$ \\
\hline M & 54 & $\begin{array}{c}\text { Bilateral fibrocaseous tuberculosis with } \\
\text { left apical cavitation }\end{array}$ \\
\hline
\end{tabular}

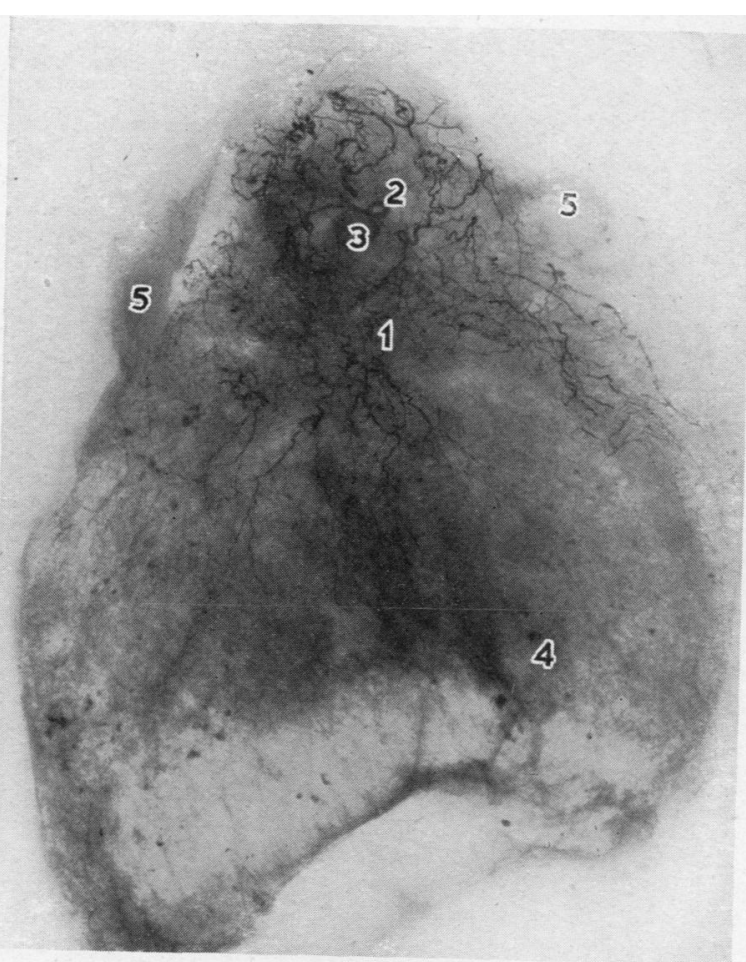

Fig. 1.-Lateral radiograph of left lung of Case 1 (hilum faces $x$-ray tube). (1) Extensive vascularity of left upper lobe (2) cavity; (3) termination of large bronchial artery in woll cavity; (4) miliary tubercles; $(5)$ thickened pleura. One-third
normal size.

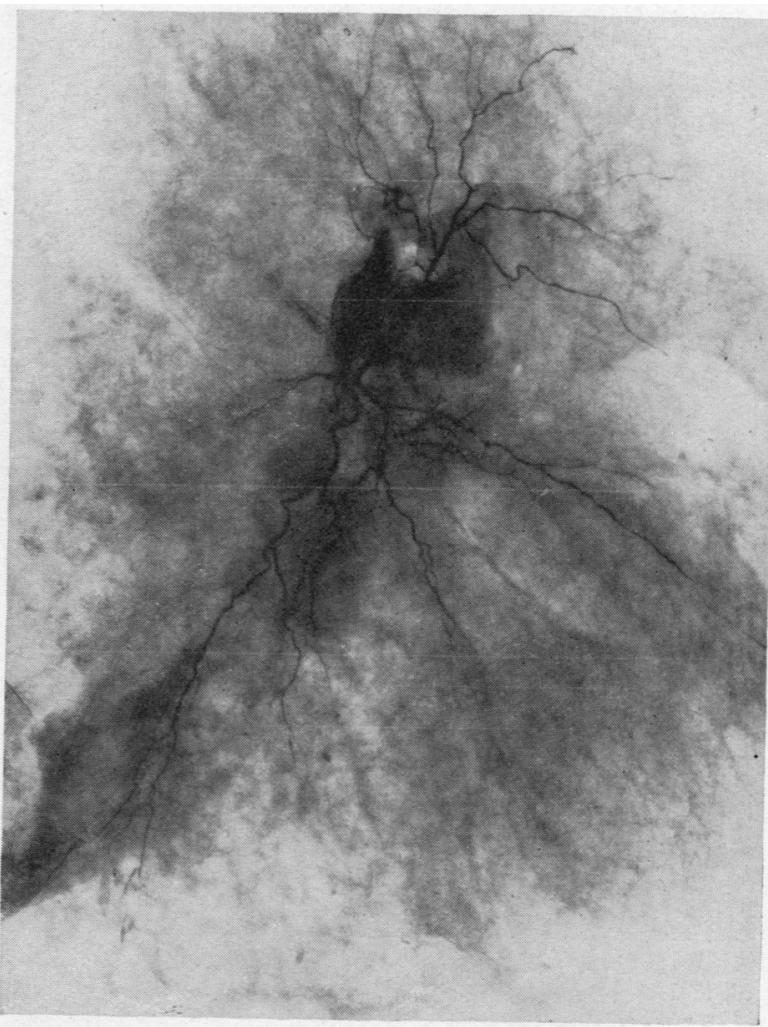

Fig. 2.-Normal pattern of left bronchial arteries seen in a lateral view of a left lung (hilum faces $x$-ray tube). Half normal size.

The details of method have been described by Cudkowicz and Armstrong (1951).

The bronchial arteries were injected via the aorta with a radio-opaque medium too coarse to traverse the capillary bed. Radiographical and histological examinations were carried out: Histologically the injection mass was recognized as a black granular medium in the lumina of the bronchial arteries, which thus differentiated them from the uninjected pulmonary vessels.

\section{RESULTS}

Radiology.-The most uniform feature observed in these lungs was the distortion, tortuosity, and remarkable proliferation of the bronchial arteries to frankly tuberculous areas.

The normal radiological pattern of the left bronchial arteries is shown in Fig. 2. The radiographs from Case 1 are shown in Figs. 1 and 3. Fig. 3 shows three large bronchial arteries of more than 4 $\mathrm{mm}$. in diameter entering the right hilum, and two even larger vessels coursing to the left. A largish artery branches off the uppermost of the three right 
bronchial arteries to supply a tuberculous right hilar lymph node. The stroma of the gland has filled with the injection medium. Scattered across both lung fields are many miliary tubercles, particularly in the upper lobes. The left upper lobe shows fibro. caseous cavitation near the apex. The right upper lobe is en physematous-and bullae can be seen at the periphery. The bronchial arteries in the right upper lobe, in spite of their original large size, show reduction in calibre peripherally and fail altogether to reach the areas of bullous emphysema. The middle, and lower lobes is normal. The pattern of the bronchial arteries in the right,

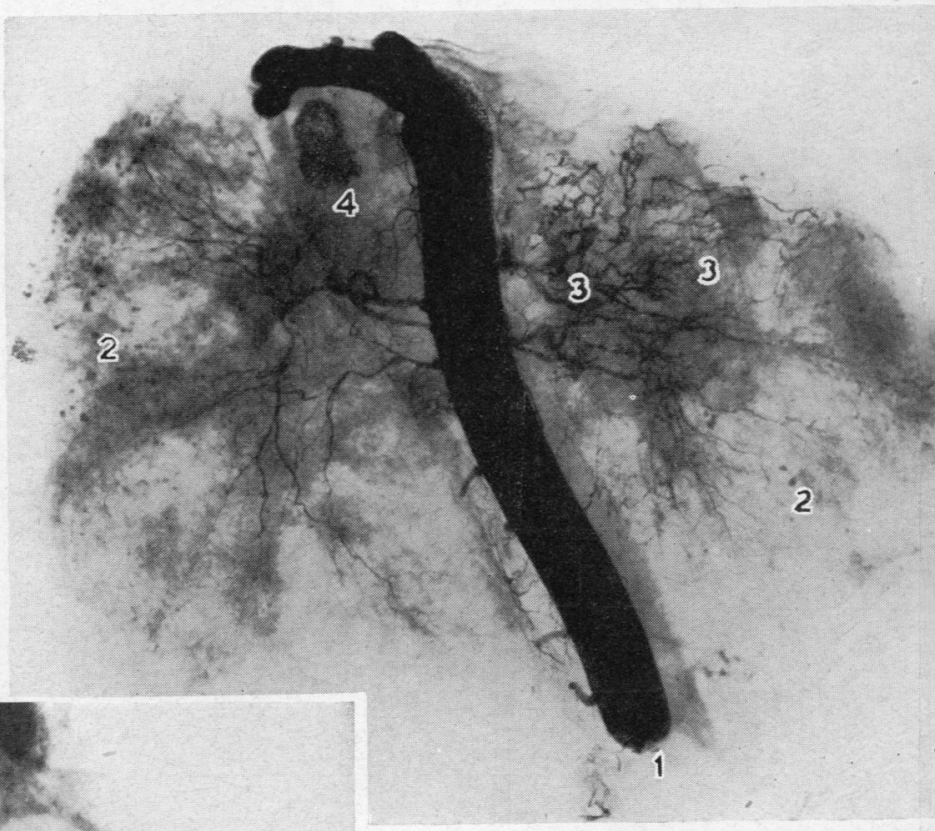

Fig. 3.-Radiograph (Case 1) of both lungs. (Left ФQ apical fibrocaseous tuberculosis and bilateral miliary dissemination.) Extensive enlargement $\vec{c}$ of the bronchial arteries is seen particularly in $G$ the left upper lobe. (1) Aorta; (2) miliary $N$ tubercles; (3) plexiform enlargement of the bronchial arteries; (4) lymph node. One-fifth $\square$ normal size.

FIG. 5.-Lateral radiograph of right lung (Case 3) (Right apical tuberculous cavitation and non-응 tuberculous terminal bronchopneumonia.) (1) Enlarged and tortuous bronchial arteries; 요 (2) cavity; (3) normal-sized bronchial arteries in unaflected areas. Two-thirds normal size.

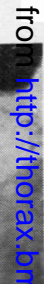

2 (1) Enlarged and tortuous bronchial arteries; (2) bismuth-filled aorta; (3) area of fibrocaseous tuberculosis. Two-thirds normal size.

most obvious changes in the pattern and calibre of the bronchial arteries are in evidence in the left upper lobe. Fig. 1 shows a lateral radiograph of the left lung. An extensive plexiform network of new arteries of considerable diameter reaches across that lobe and bears no resemblance to the normal bronchial arterial pattern. In some of the vessels the calibre appears to increase towards the periphery, and one very large artery terminates in the wall of the apical cavity.

Figs. 4 and 5 show similar proliferative changes in the bronchial arteries near tuberculous lung foci in Cases 2 and 3. 


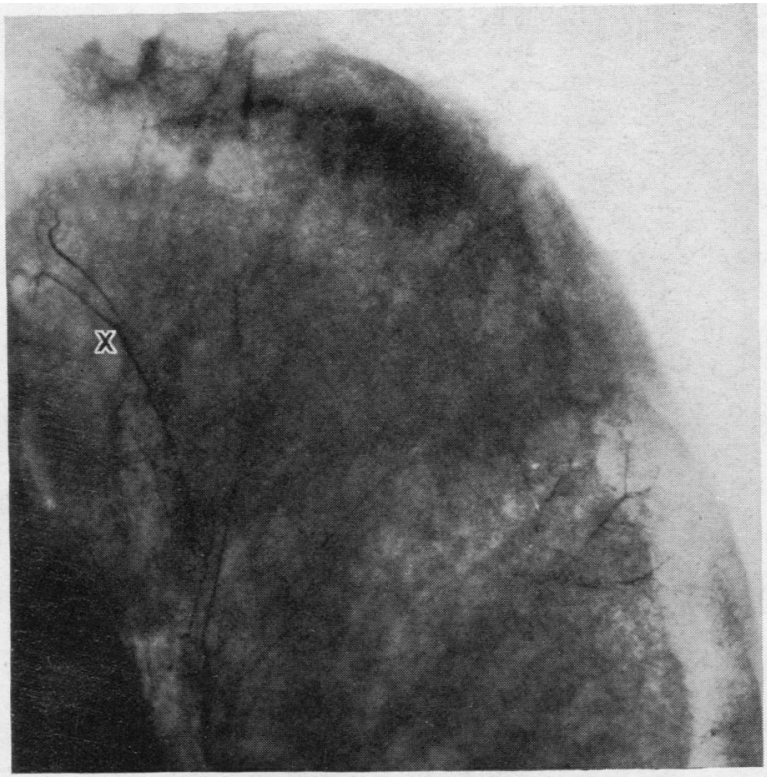

FIG. 6.-Lateral radiograph of a left upper lobe to show the normal pattern of a left apical pleural branch of the bronchial arteries (x). About normal size.

Fig. 7.-Lateral radiograph of left upper lobe in Case 4. (Left apical fibro-caseous lesion.) Enlargement of left apical pleura branch (x). Approximately normal size.

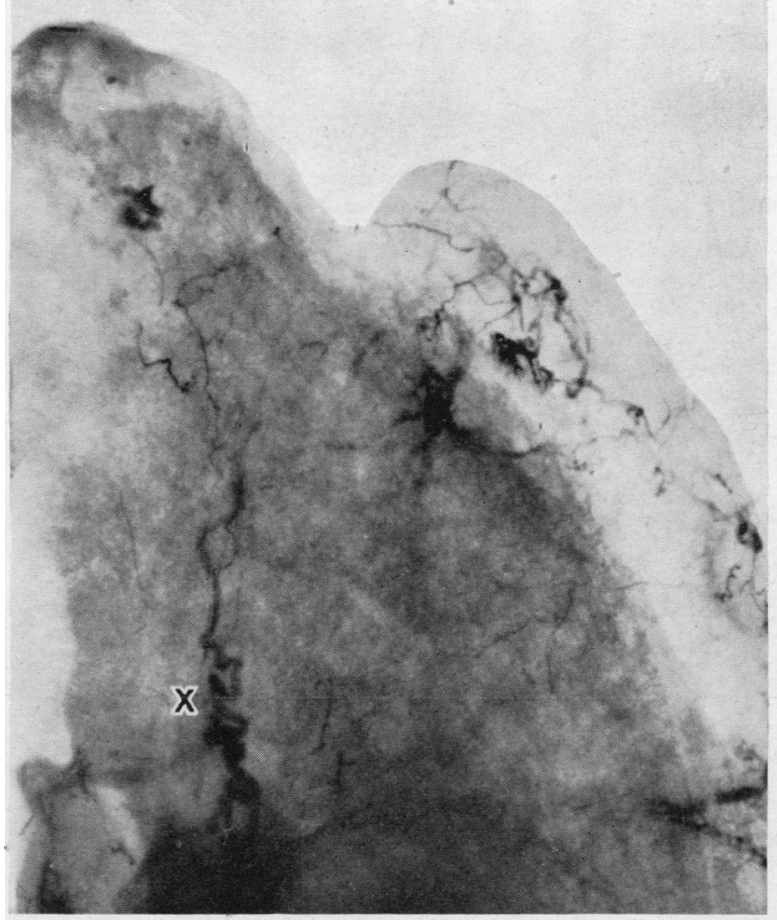

Fig. 6 shows a normal apical pleural branch, and Fig. 7 the considerable enlargement and tortuosity of that artery in Case 4 , where the tuberculous lesion was confined to the left apex.
Fig. 8 shows the changes in the bronchial arterial circulation in Case 5. The left apex shows a large cavity and the vessels in its wall. The right apex was the seat of a large caseous lesion, and the arteries extending to that area were very hypertrophied.

Histology.-One very striking lesion revealed by the histology was the gross degree of obliteration of the pulmonary artery radicles in the areas of fibrocaseous tuberculosis. The lumina were occluded by intimal proliferation and thrombosis. In the branches proximal to the lesion some recanalization of the lumina had taken place by proliferation of the vasa vasorum. These arterioles are derived from the bronchial arteries, and therefore conveyed the injection mass to the new lumina in the revascularized pulmonary artery branches (Fig. 9).

Associated with adhesions between the pleural surfaces were obliterative lesions in the visceral pleural arteries. The walls of these bronchial artery branches showed massive medial hyperplasia and intimal proliferation. Their occluded lumina

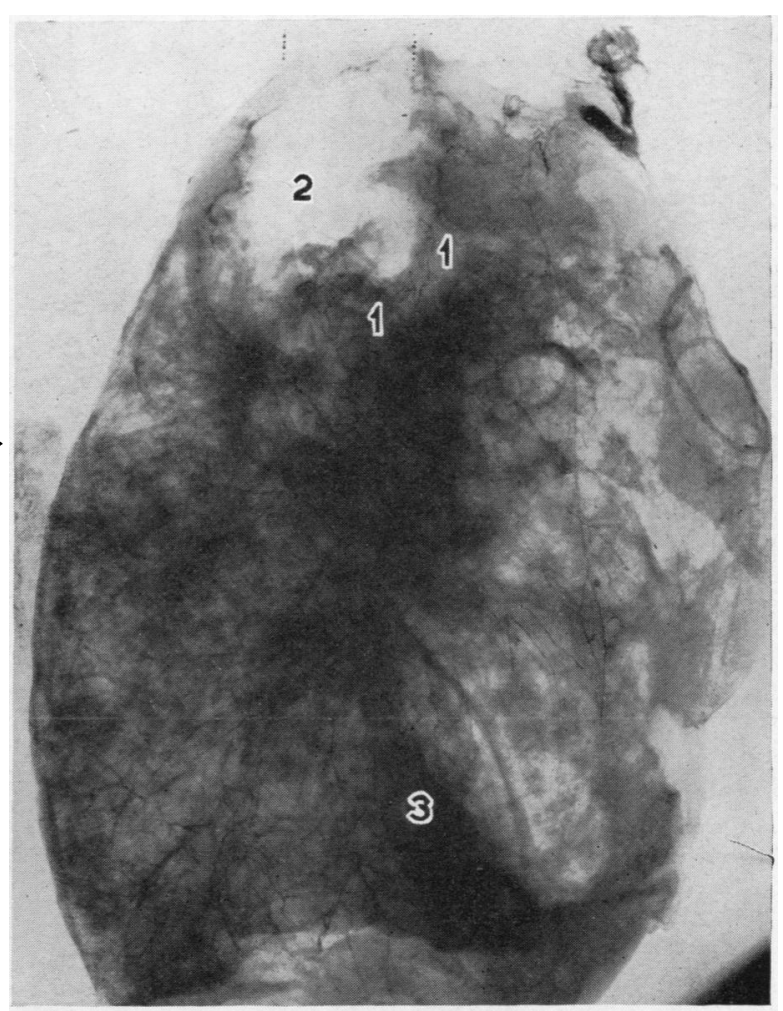

Fig. 8. - Lateral radiograph of left lung of Case 5. (Bilateral fibrocaseous tuberculosis with left apical cavitation.) (1) Network of bronchial arteries in wall of cavity; (2) cavity; (3) caseous lesion in left lower lobe. One-third normal size. 
FIG. 9.-Photomicrograph of a thrombosed pulmonary artery branch near a caseous lung focus in Case 2. (1) Pulmonary artery; (2) recanalization of pulmonary artery lumen; (3) bismuth granules; (4) proliferating vasa vasorum (derived from bronchial arteries and therefore bismuth-filled), $\times 50$.

FIG. 10.-Photomicrograph of visceral pleural arteries in Case 2 showing (1) medial hyperplasia; (2) intimal proliferation; (3) adhesion between pleural surfaces; (4) extension of parietal surfaces;
capillaries into visceral pleura, $\times 60$.

FIG . 11.-Photomicrograph of an obliterated visceral pleural artery in Case 3. The lumen of this vessel is recanalized by capillaries which are derived from arterioles in the adherent parietal pleura, since they are not filled with bismuth, $\times 80$.
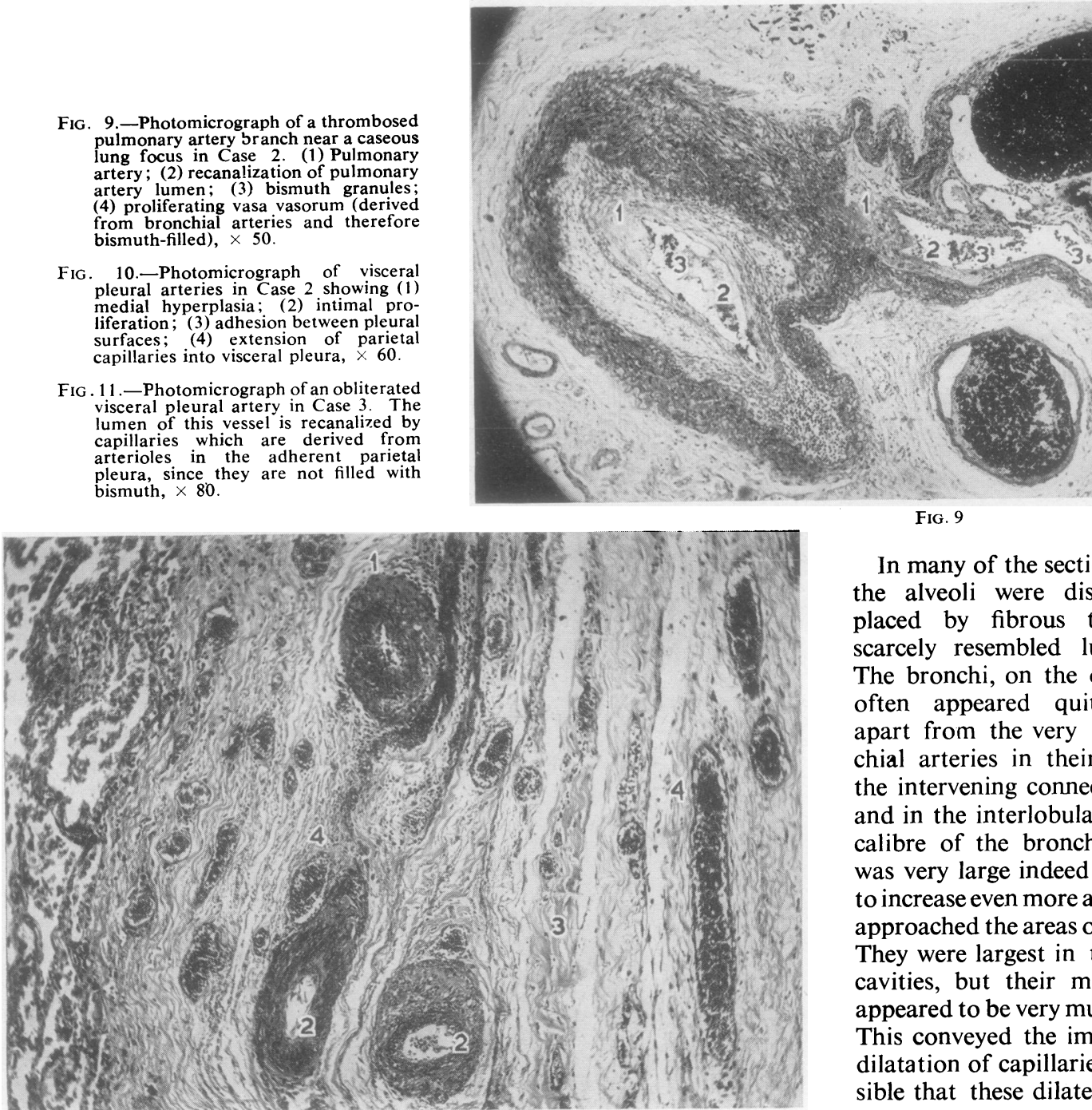

FIG. 9

In many of the sections studied $\mathbb{D}$ the alveoli were distorted, re- $\frac{\overrightarrow{0}}{\mathbb{D}}$ placed by fibrous tissue, and 3 scarcely resembled lung tissue. $\underline{\text { }}$ The bronchi, on the other hand, $\vec{\theta}$ often appeared quite normal, apart from the very large bron-? chial arteries in their coats. In the intervening connective tissue, and in the interlobular septa, theo calibre of the bronchial arterieso was very large indeed and tended $\stackrel{Q}{\circ}$ to increase even more as the vessels $\overrightarrow{\vec{O}}$ approached the areas of caseation. 3 They were largest in the walls of cavities, but their muscle coats: appeared to be very much thinned. This conveyed the impression ot음 dilatation of capillaries. It is possible that these dilated bronchiats

FIG 10

were, however, opened up again by capillaries from the parietal pleural arteries which entered them through the adhesions (Figs. 10 and 11 ).

In contrast with the endarteritic changes in the pulmonary arteries and in the visceral pleural arteries was the dilatation of the bronchial arteries in the tuberculous areas. It would, indeed, have been difficult to differentiate the bronchial vessels from large pulmonary artery branches in these sections, had the bronchial arteries not been outlined by the contrast medium.

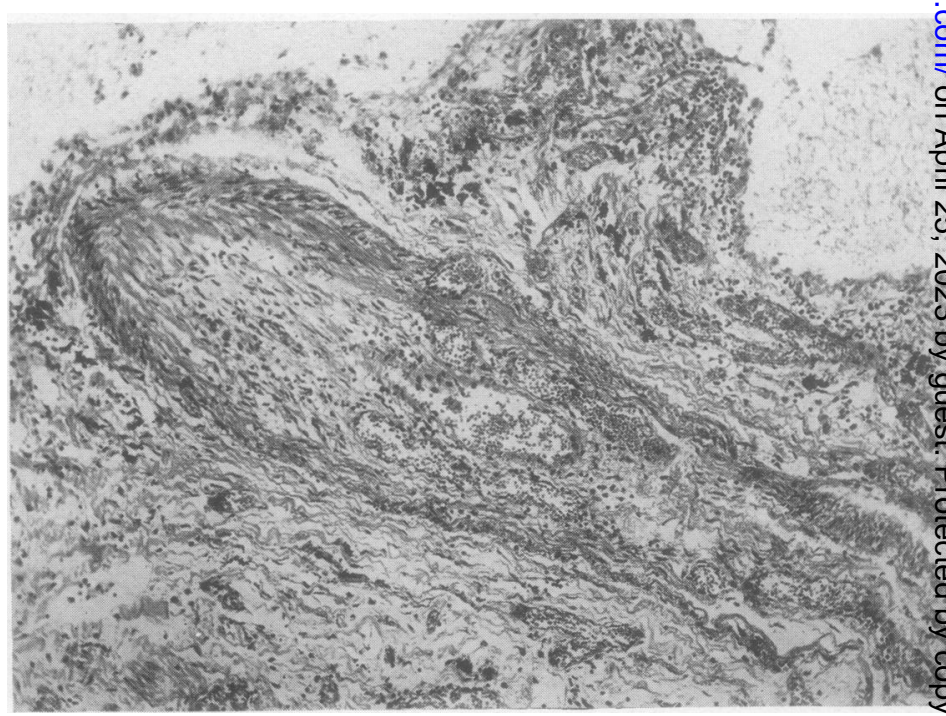

Fig. 11 


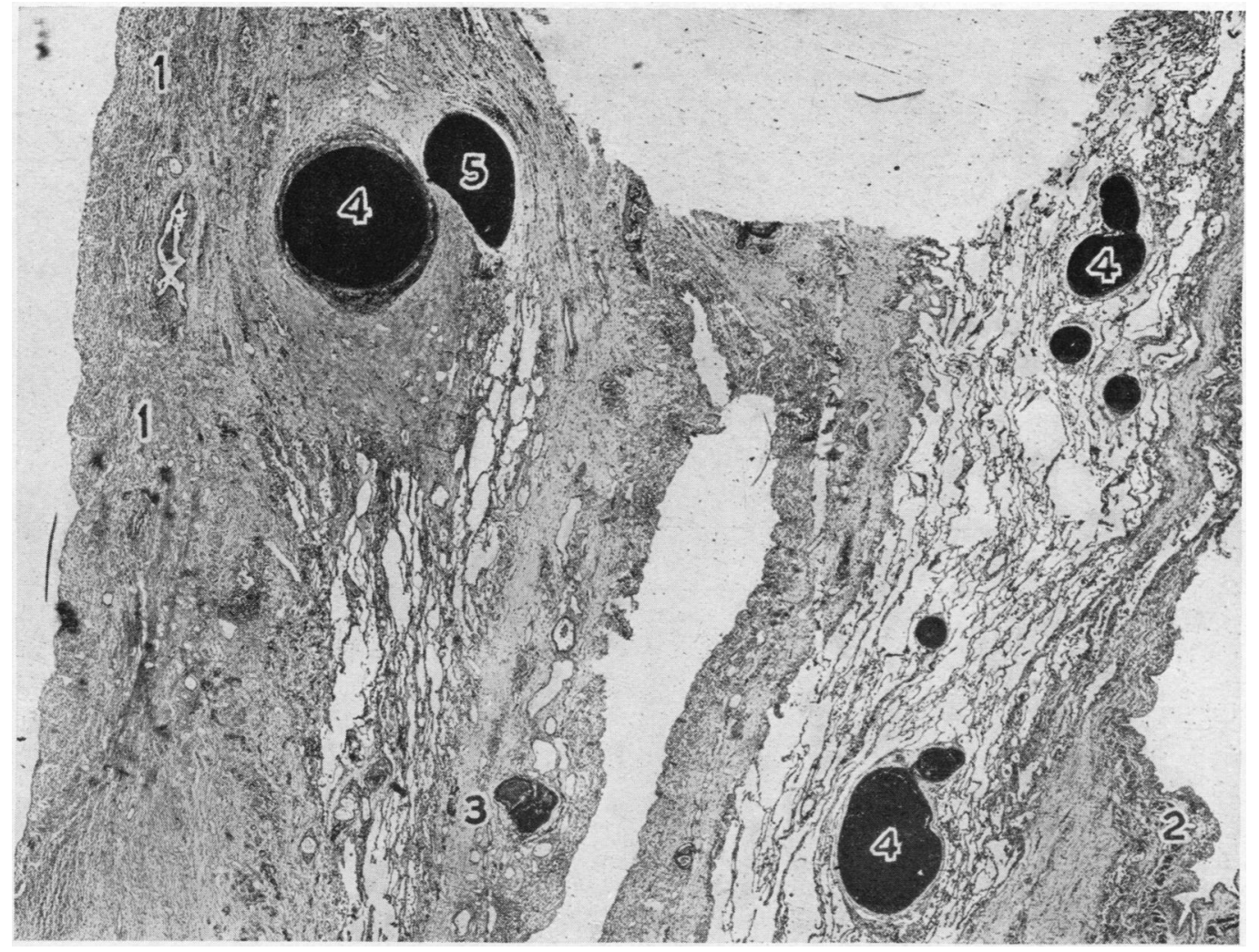

Fig. 12.-Photomicrograph from edge of a tuberculous cavity in Case 2. (1) Cavity wall; (2) bronchial mucosa; (3) pulmonary artery; (4) bronchial arteries; (5) very dilated bronchial arteriole, $\times 19$.

arterioles have in the past been considered to be aneurysmal dilatations of the pulmonary arterioles. The pulmonary arteries near caseating areas have, in the present cases, been found to be thrombosed (Fig. 12).

The left lower lobe of Case 1 showed many polymorphonuclear leucocytic exudates in the alveoli, as well as many coalescing miliary tubercles. The pulmonary arterioles near the tubercles showed polymorphonuclear infiltration of their coats and organizing thrombi in their lumina. No injected arterioles were present in the tubercles themselves, but the bronchial arterioles in their immediate neighbourhood were dilated and patent (Fig. 13).

\section{Discussion}

The present study confirms the radiographic observations of Wood and Miller (1938). Enlarged bronchial arteries are present in tuberculous lungs and tuberculous cavities have a rich bronchial blood supply. The capillary dilatations in the cavity walls are probably the aneurysmal dilatations of Rasmussen (1868 and 1869), referred to by Calmette (1923) and Kaufmann (1929) who thought they arose in pulmonary arterioles. The pulmonary artery branches appear to have no part to play in the blood supply of caseating tuberculous lung areas, as they undergo thrombosis in the early stages of the disease. Some recanalization of the occluded lumina of the pulmonary arteries occurs proximal to the tuberculous foci and is accomplished by the proliferation of the vasa vasorum of the pulmonary arteries, which are radicles of the bronchial arteries. Free anastomoses between the two patent systems were not observed in the present cases.

Thrombosis of the pulmonary artery and compensatory enlargement of the bronchial arteries accords with the contention of Karsner and Ash (1912) who showed that such enlargement follows a fall in pressure in the pulmonary artery. Wright (1938) advanced a teleological view concerning the cause of the proliferation of the bronchial arteries. He suggested that collagen proliferation in the lungs, irrespective of the cause, demands a profuse arterial blood supply. Pagel's concept of tubercle formation from elements of connective tissue which have an inherent tendency to vessel formation might further explain the proliferation of the bronchial arteries in pulmonary tuberculosis.

It is impossible to say what part the tuberculous infection itself plays in initiating its own oxygen supply, yet the dilatation of the bronchial arterioles near areas of tuberculous caseous necrosis, which 
FIG. 13. - Photomicrograph of a miliary tubercle in Case 1 showing (1) dilated bronchial arteriole containing bismuth in its lumen, and situated near the tubercle; (2) giant cell, $\times 60$.

are not in direct communication with patent bronchi, suggests that a source of oxygen is available for tubercle bacilli at least at the periphery of such areas.

It seems, therefore, that both the infection and the tissue defences require the bronchial circulation for their blood supply. The presence of extensive systemic arterial capillaries in the adhesions between the pleural surfaces and the tendency of these capillaries to recanalize the obliterated pleural arteries indicate that a profuse quantity of arterial blood is present in the neighbourisood of tuberculous foci in the periphery of such lungs.

The patency of the bronchial arteries near miliary foci and their proliferation in fibrocaseous lungs should allow streptomycin or other drugs administered systemically to reach the tuberculous areas. The rich capillary network in adhesions, which appears to augment the blood flow through the visceral pleura, is not without significance, and the loss of these additional channels should be considered when chemotherapy is combined with collapse therapy and adhesion section.

Finally, surgical measures to combat profuse haemoptysis are unlikely to be successful if they are concentrated upon the pulmonary arteries alone.

\section{SUMMARY}

The vasculature of the lungs in pulmonary tuberculosis has been examined in necropsy material with the aid of the injection of the bronchial arteries with a contrast medium.

Radiography of the injected lungs showed gross enlargement of the bronchial arteries in the affected areas, many more being clearly visible than in corresponding normal lungs. Histological examination revealed thrombosis of the pulmonary artery branches in the same areas and gross dilatation of the bronchial vessels. The walls of tuberculous cavities were found to have only a bronchial arterial blood supply. Dilatation of the bronchial arteries was observed near miliary tubercles. In pleuraP adhesions the visceral pleural arteries, which are derived from the bronchial arteries, were occludect but their lumina were revascularized by capillaries derived from parietal pleural arterioles.

The thrombosed pulmonary artery branche proximal to the tuberculous foci frequently showed recanalization of their lumina by the vasa vasorum which originated from the bronchial arteries. The clinical significance of these findings has bee considered.

I wish to thank Dr. J. B. Armstrong for his help wit the first case, Dr. J. Crofton for his interest in this study Dr. C. V. Harrison for providing the post-mortero facilities, Miss M. S. MacAdam for taking the radiō. graphs, Mr. J. Griffin, A.I.M.L.T., and his team fog preparing the sections, and Mr. E. V. Willmott, F.R.P.S and $\mathrm{Mr}$. K. Moreman, A.R.P.S., for the radiographs and photomicrographs.

\section{REFERENCES}

Boyd, W. (1950). The Pathology of Internal Diseases, 5 th ed., p. 20

London.
Calmette, A. (1923). Tubercle Bacillus Infection and Tuberculosis in Mun and Animals, trans. W. Soper and G. Smith, p. 191, Baltimore.

Coryllos, P. N. (1933). J. Amer. med. Ass., 100, 480

Cournand, A., and Richards, D. W. (1941). Amer. Rev. Tuber 44, 123 .

Cudkowicz, L., and Armstrong, J. B. (1951). Thorax, 6, 343. ㅈ

Dubos, R. J. (1950). Amer. J. Med., 9, 573.

Ghoreyeb, A. A., and Karsner, H. T. (1913). J.exp. Med., 18, 5 \&

Karsner, H. T., and Ash, J. E. (1912). J. med. Res., 27, 205.

Karsner, H. T., and Ash, J. E. (1912). J. med. Res., 27, 205.
Kaufmann, E. (1929). Pathology for Students and Practitione $\$$, trans. S. P. Reimann, vol. 1, p. 449, London.

Kayne, G. G., Pagel, W., and O'Shaughnessy, L. (1948). Pulmonaty Tuberculosis, 2nd ed., p. 210, London, Oxford University Press. Rasmussen, V. (1868). Hospitalstidende, 11, 33, 45

(1869). Ibid., 12, 41, 45.

Rich, A. R. (1944). The Pathogenesis of Tuberculosis, Springfield, IT Steinberg, I., McCoy, H. I., and Dotter, C. T. (1950). Amer. ReD. Tuberc., 62,353

Wood, D. A., and Miller, M. (1938). J. thorac. Surg., 7, 649.

Wright, R. D. (1938). J. Path. Bact., 47, 489. 